\title{
DEGRADASI KATALITIK ZAT WARNA METIL JINGGA MENGGUNAKAN KATALIS OKSIDA MANGAN MANGANOSITE
}

\author{
Mokhamad Subkhan, Amir Awaluddin, Presetya, Siti Saidah Siregar, Riska Anggraini \\ Jurusan Kimia, FMIPA, Universitas Riau, Pekanbaru, Riau, Indonesia \\ e-mail: amir.awaluddin@lecturer.unri.ac.id
}

\begin{abstract}
Preparation of manganese oxide by sol-gel method and its application as a catalyst for methyl orange (MO) degradation was carried out using hydrogen peroxide as an oxidant.The characterization of manganese oxide was conducted using X-Ray Diffraction and Scanning Electron Microscope. The effect of initial concentration of $M O$ was examined. Degradation efficiency was decrease with increasing the concentration of MO. The degradation kinetics of MO followed the second-order reaction kinetics.
\end{abstract}

Keywords: methyl orange, degradation, sol-gel

\section{PENDAHULUAN}

Produksi zat warna dunia mencapai lebih dari 700.000 ton per tahun. Jumlah ini akan terus mengalami peningkatan dengan semakin banyaknya aplikasi zat warna pada berbagai produk seperti kosmetik, ppercetakan, tekstil, kertas serta industri lainnya. Pada proses pewarnaan hanya 85 $\%$ zat warna yang digunakan dan sisanya 15 $\%$ terbuang sebagai limbah (Park dan Choi, 2003). Limbah zat warna yang dibuang ke lingkungan tanpa pengolahan lebih lanjut, bersifat racun dengan potensi efek karsinogenik dan genotoksik (Liu dkk., 2015). Zat warna memiliki banyak variasi dan telah dimodifikasi sedemikian rupa sehingga awet dan sulit terdegradasi oleh paparan sinar matahari, air dan kondisi ekstrim lainnya (Park and Choi, 2003). Zat warna yang berbahaya diantaranya adalah metil jingga (MO). MO merupakan senyawa organik aromatik yang bersifat stabil dan sulit didegradasi secara alami. Oleh karena itu diperlukan upaya untuk mendegradasi MO agar akibat buruk dari limbah MO ini dapat diminimalisir.

Secara umum, ada tiga metode yang digunakan untuk degradasi MO yaitu metode biologi, fisika dan kimia. Metode biologi (bioremidiasi) banyak digunakan karena ramah lingkungan dan murah. Namun memiliki kelemahan yaitu membutuhkan waktu degradasi yang lama. Adsorpsi yang merupakan salah satu metode fisika yang biasa digunakan, relatif sederhana dan cukup efektif untuk digunakan, tapi pada proses ini yang terjadi hanya transfer limbah zat warna. Metode kimia yang berbasis fenton reaksi memiliki keunggulan yaitu dapat mendegradasi senyawa organik dengan cepat menjadi produk yang tidak berbahaya seperti $\mathrm{CO}_{2}$ dan $\mathrm{H}_{2} \mathrm{O}$ menggunakan radikal yang sangat reaktif seperti $\mathrm{OH} \bullet$.

Oksida logam merupakan suatu katalis heterogen yang banyak digunakan pada metode fenton. Salah satu oksida logam yang digunakan untuk reaksi fenton adalah oksida mangan. Oksida ini memiliki 
keunggulan yaitu ramah lingkungan, relatif murah dan memiliki aktifitas katalitis yang tinggi utuk mendegradasi senyawa organik. Oksida mangan diketahui memiliki berbagai struktur yaitu struktur berlapis dan berongga yang memiliki aktifitas katalitik yang berbeda-beda. Morfologi permukaan serta sifat-sifat fisik lainnya sangat berpengaruh terhadap aktifitas katalitik oksida mangan.

Berbagai metode telah berhasil digunakan untuk mensintesis oksida mangan. Salah satu metode sintesis oksida mangan yang umum digunakan selain metode hidrotermal (Cheng dkk., 2014), refluk (Cui dkk., 2011) dan keramik (Siregar dan Awaluddin, 2018) adalah metode sol-gel (Awaluddin dkk., 2017). Metode sol-gel menghasilkan produk dengan homogenitas tinggi karena reagenreagen dicampur pada tingkat molekuler dan suhu yang digunakan relatif rendah.

Pada penelitian ini, oksida mangan dipreparasi dari $\mathrm{KMnO}_{4}$ dan glukosa dengan metode sol-gel dan diaplikasikan sebagai katalis untuk degradasi MO. Hasil penelitian Awaluddin dkk. (2017) menunjukkan potensi oksida mangan untuk degradasi zat warna yaitu metilen blue (MB). Oksida mangan yang digunakan yaitu tipe cryptomelane yang dipreparasi dari $\mathrm{KMnO}_{4}$ dengan reduktor asam sitrat dan glukosa menggunakan metode sol-gel. Zat warna MB dan MO memiliki perbedaan yaitu MB bersifat kationik sedangkan MO bersifat anionik. Aplikasi oksida mangan sebagai katalis untuk degradasi zat warna khususnya MO belum banyak dilakukan. Oleh karena itu diharapkan dengan sifat dan struktur dari oksida mangan yang disintesis dengan metode sol-gel yang dipreparasi dari $\mathrm{KMnO}_{4}$ dan glukosa ini dapat digunakan sebagai katalis untuk degradasi
MO dengan menggunakan hidrogen peroksida sebagai oksidan.

\section{METODOLOGI PENELITIAN}

\section{Alat dan bahan}

Alat yang digunakan dalam penelitian ini adalah XRD (Rigaku), SEM model EVO-50 (ZEIZZ), Neraca analitik ABJNM/ABS-N (KERN), Oven (Memmert), Furnace (Gallenkamp), Spektrofotometer Vis (Optima-SP3000), Hot plate stirrer (VELP), dan peralatan gelas yang umum dipakai.

Bahan-bahan yang digunakan dalam penelitian ini adalah $\mathrm{KMnO}_{4}$ keluaran Merck (Cat. No. 105082), glukosa keluaran Merck (Cat. No. 108337), $\mathrm{HCl}$ pekat keluaran Merck (Cat. No. 100317), Methyl Orange keluaran Merck (C.I.13025), $\mathrm{H}_{2} \mathrm{O}_{2}$ $30 \%$ keluaran Merck (Cat. No. 108597), dan bahan-bahan kimia lain sesuai dengan prosedur kerja.

\section{Sintesis oksida mangan}

Sintesis oksida mangan dilakukan dengan cara 47,25 gram glukosa $\left(\mathrm{C}_{6} \mathrm{H}_{12} \mathrm{O}_{6}\right)$ ditambahkan ke larutan $\mathrm{KMnO}_{4}$ yang dibuat dengan melarutkan 27,65 gram $(0,175 \mathrm{~mol}) \mathrm{KMnO}_{4}$ dalam 1 liter akuades sambil diaduk dan akan terbentuk sol $( \pm 2$ menit) yang kemudian berubah menjadi gel. Gel yang telah terbentuk $( \pm 1$ jam$)$, kemudian dicuci dengan $250 \mathrm{~mL}$ akuades sebanyak empat kali dan keringkan pada temperatur $110^{\circ} \mathrm{C}$ selama semalaman. Hasil yang diperoleh dikalsinasi pada temperatur $700^{\circ} \mathrm{C}$ selama dua jam. Produk yang terbentuk dicuci masing-masing dengan 10 $\mathrm{mL} \mathrm{HCl}$ 0,1 $\mathrm{M}$ dan akuades. Produk dikeringkan pada temperatur $110^{\circ} \mathrm{C}$ untuk siap dikarakterisasi. Karakterisasi dilakukan dengan menggunakan XRD untuk menentukan struktur, tingkat 
kristalinitas dan tingkat kemurniannya dan analisis morfologi menggunakan SEM.

\section{Degradasi metil jingga}

Larutan MO (10 ppm) sebanyak 100 $\mathrm{mL}$ dimasukkan ke dalam Beaker kemudian ditambahkan $\mathrm{HCl}$ 0,1 M sampai diperoleh larutan dengan $\mathrm{pH}$ 2. Oksida mangan yang telah disintesis ditambahkan sebanyak $10 \mathrm{mg}$ dan diaduk dengan kecepatan 400 rpm selama 30 menit pada suhu ruang. Hidrogen peroksida 30\% ditambahkan sebanyak $10 \mathrm{~mL}$ untuk memulai proses reaksi. Campuran diambil pada menit ke 5, 10, 15, 20, 25, 30, 60 dan 90. Setiap pengambilan sampel didinginkan untuk menghentikan reaksi. Konsentrasi MO yang tersisa dinalisis menggunakan spektrofotometer. Prosedur yang sama dilakukan untuk kondisi larutan pada $\mathrm{pH} 4$ dan 6.

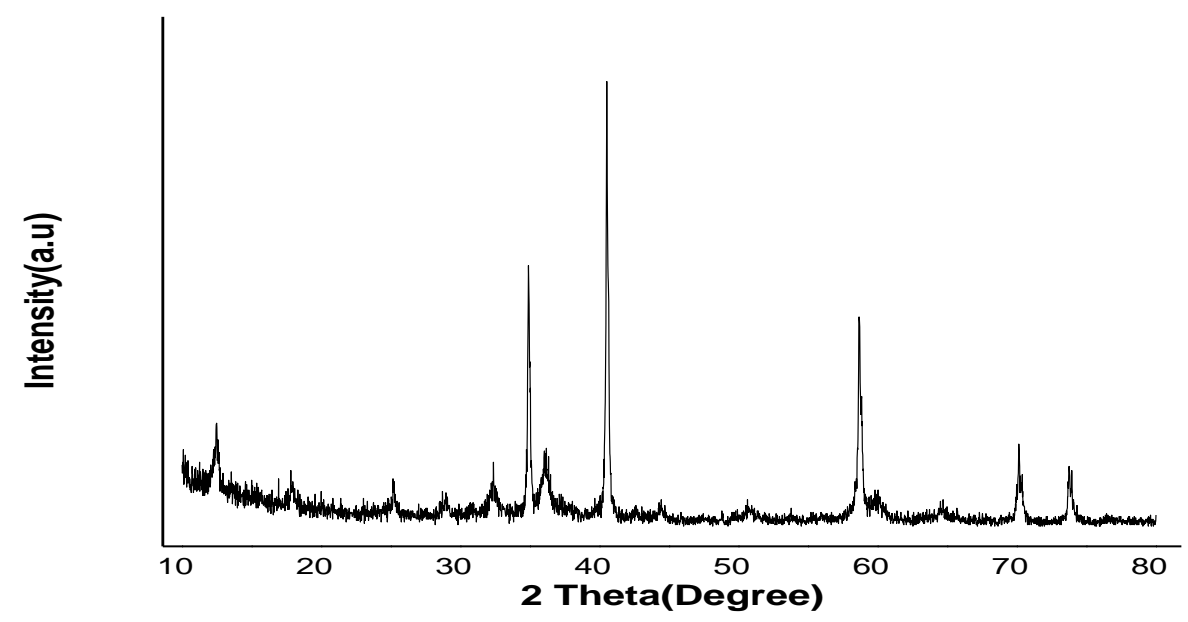

Gambar 1. Difraktogram XRD oksida mangan hasil sintesis

HASIL DAN PEMBAHASAN

Metode Difraksi Sinar-X memberikan informasi mengenai struktur dan tingkat kristalinitas dari suatu padatan yang dihasilkan dalam bentuk pola difraksi (difraktogram). Pola difraksi dari mangan oksida yang diperoleh disajikan pada Gambar 1. Oksida mangan hasil sintesis yang disintesis dengan metode sol-gel menggunakan prekursor $\mathrm{KMnO}_{4}$ dan glukosa dengan perbandingan mol 2: 3 menghasilkan puncak-puncak difraksi pada sudut $2 \theta$ yaitu 34,90 (2,57 $\AA) ; 40,53$ (2,22 $\AA)$; 58,71 (1,57 ̊); 70,19 (1,34 ̊); dan $73,79(1,28 \AA)$ dengan bidang refleksi (111); (200); (220); (311); dan (222) yang merupakan karakteristik dari manganosite. 


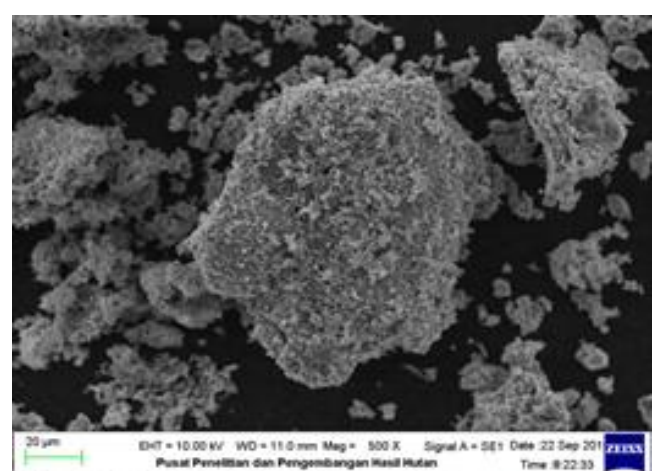

(a)

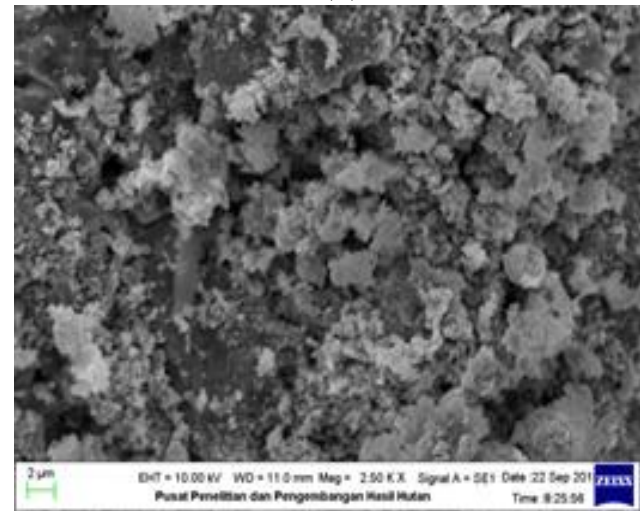

(c)

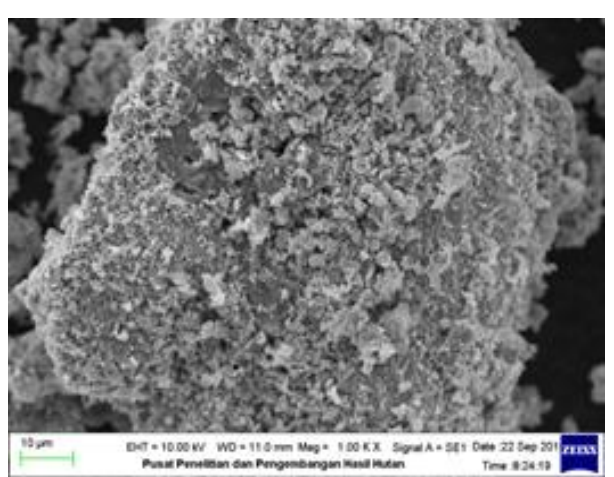

(b)

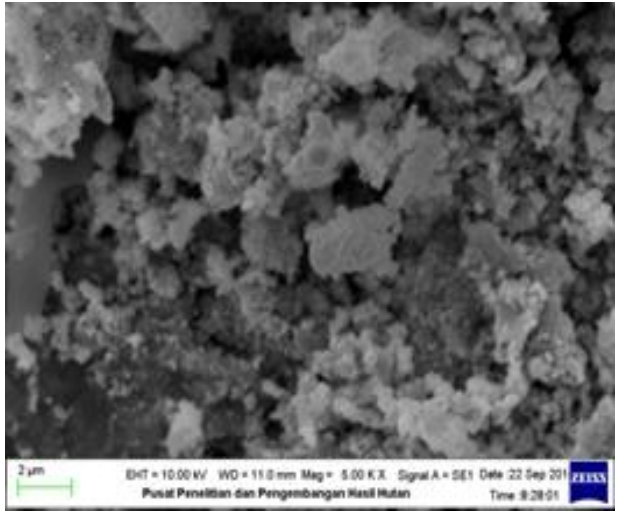

(d)

Gambar 2. Morfologi mangan oksida hasil sintesis: (a) perbesaran 500x, (b) perbesaran 1.000x, (c) perbesaran $2.500 \mathrm{x}$ dan $(\mathrm{d})$ perbesaran $5.000 \mathrm{x}$

Karakterisasi dengan SEM pada penelitian ini dilakukan untuk mengetahui morfologi permukaan dari oksida mangan hasil sintesis dengan metode sol-gel. Pada Gambar 2. dengan perbesaran hingga 5000x memperlihatkan bentuk butiran dengan ukuran tidak seragam dan tersusun tidak teratur.

Pada penelitian ini, variasi konsentrasi awal MO dilakukan untuk mengetahui pengaruhnya pada proses degradasi. Zat warna MO bersifat anionik dan bermuatan negatif. Oleh karena sifat ini, maka kondisi yang ideal dari reaksi degradasi MO yaitu pada kondisi asam dan disekitar permukaan katalis bermuatan positif. Pada Gambar 3 dapat dilihat persentase degradasi MO menurun dengan naiknya konsentrasi awal MO. Semakin tinggi konsentrasi awal MO laju degradasi semakin menurun. Hasil degradasi terbesar pada menit ke- 90 yaitu $92,09 \%$. 


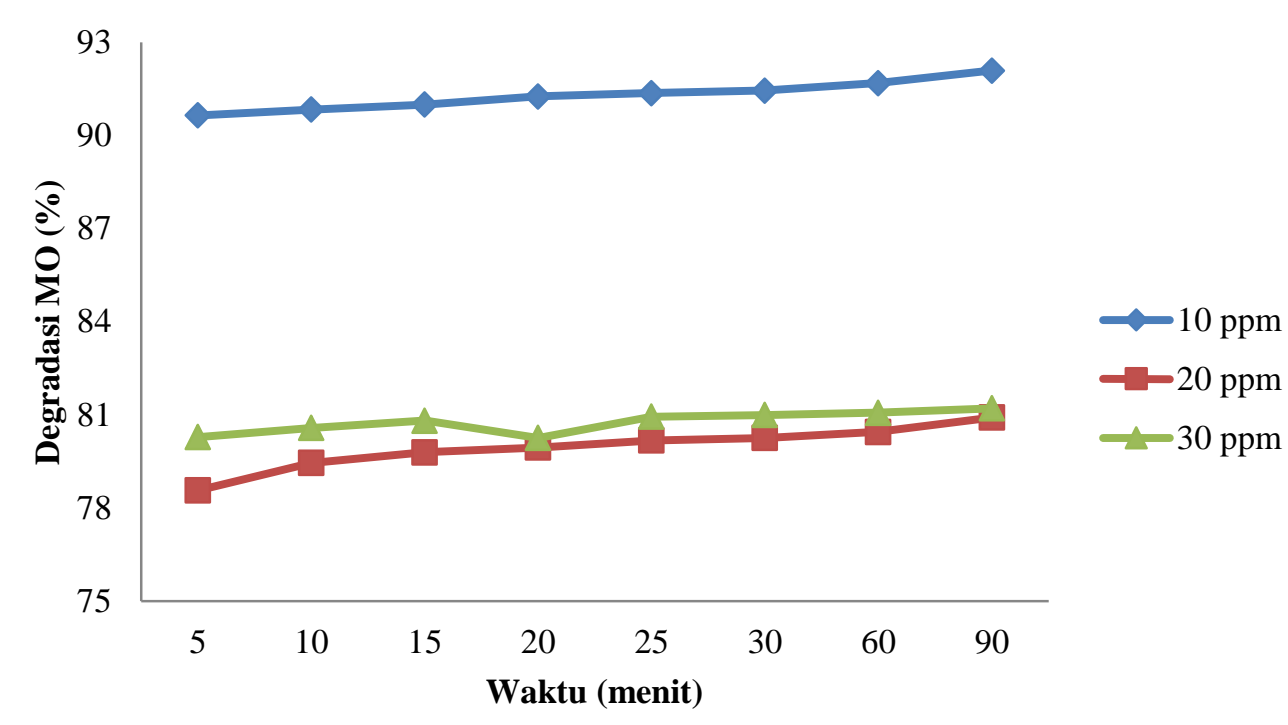

Gambar 3. Pengaruh konsentrasi awal MO pada degradasi menggunakan kaalis oksida mangan hasil sintesis. Kondisi reaksi: katalis $=0,03 \mathrm{~g}, \mathrm{H}_{2} \mathrm{O}_{2}=10 \mathrm{~mL}, \mathrm{pH}$ awal $=2$, $\mathrm{T}=$ suhu ruang

Pada penelitian ini, kinetika reaksi orde nol, ke-satu, dan ke-dua digunakan untuk studi kinetika degradasi MO menggunakan katalis oksida mangan. Berdasarkan perbandingan koefisien regresi $\left(\mathrm{R}^{2}\right)$ yang diperoleh pada Gambar 4 . (a)-(c) dapat dilihat nilai $\mathrm{R}^{2}$ untuk orde ke-

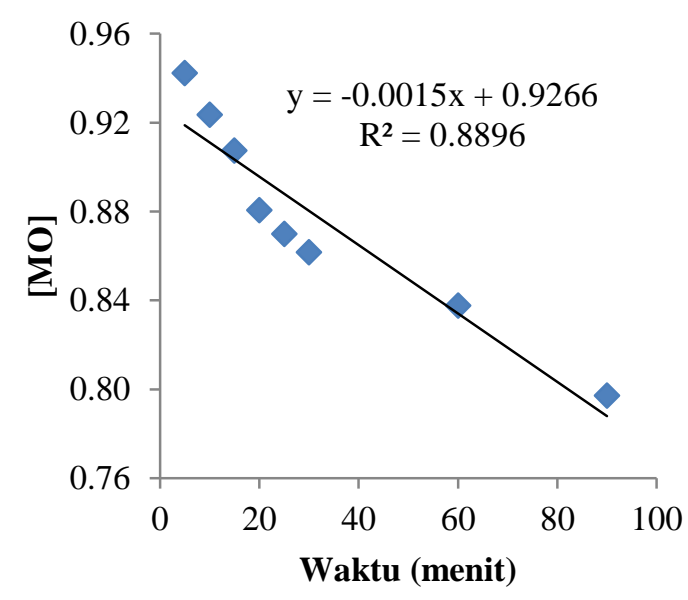

(a) dua yaitu 0,9043 . Nilai $\mathrm{R}^{2}$ ini lebih baik dibandingkan kinetika reaksi orde nol $\left(\mathrm{R}^{2}=\right.$ $0,8896)$ dan orde ke-satu $\left(\mathrm{R}^{2}=0,9043\right)$. Hasil ini menunjukkan bahwa kinetika degradasi MO mengikuti kinetka orde kedua.

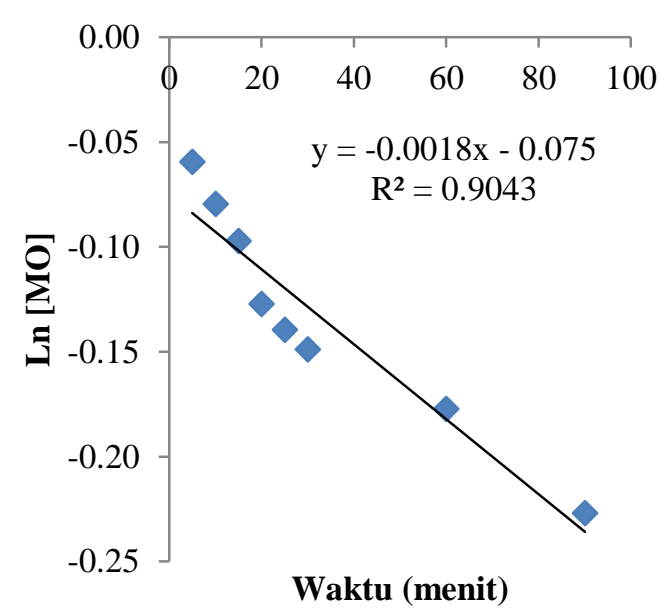

(b) 


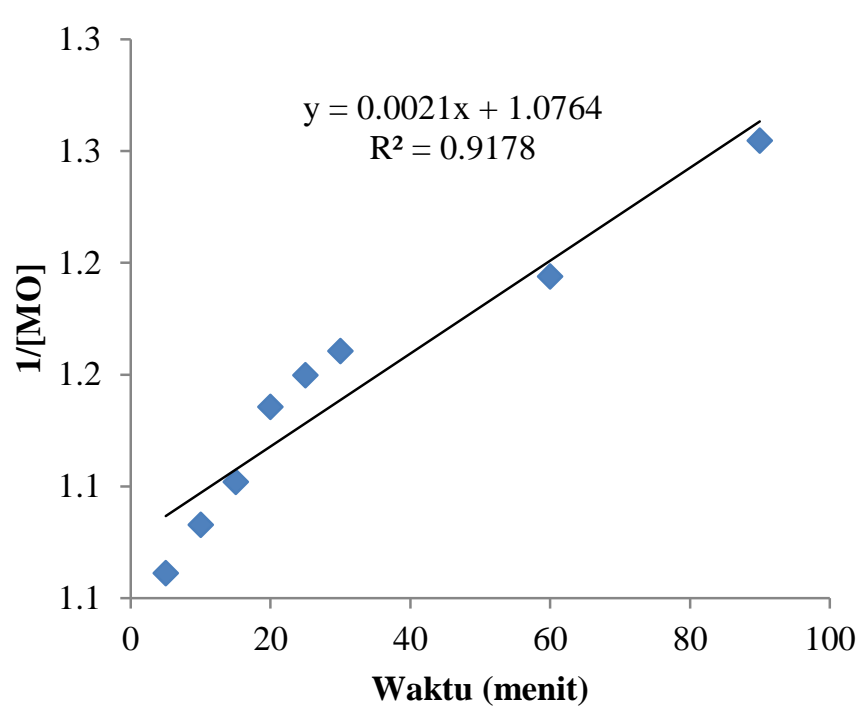

(c)

Gambar 4. Kinetika reaksi orde nol, ke-satu, dan ke-dua untuk degradasi MO dengan katalis oksida mangan hasil sintesis. Kondisi reaksi: $\mathrm{MO}=10 \mathrm{mg} / \mathrm{L}$, katalis $=0,03 \mathrm{~g}, \mathrm{H}_{2} \mathrm{O}_{2}=10 \mathrm{~mL}$, $\mathrm{pH}=2, \mathrm{~T}=$ suhu ruang

\section{PENUTUP}

\section{Kesimpulan}

Pada penelitian ini, degradasi MO dengan katalis oksida mangan hasil sintesis yaitu manganosite dilakukan pada berbagai konsentrasi awal MO. Semakin tinggi konsentrasi awal MO, laju degrdasi semakin menurun. Persentase degradasi maksimun berlangsung pada konsentrasi awal MO 10 mg/L. Reaksi degradasi MO menggunakan katalis manganosite mengikuti kinetika reaksi orde ke-dua yang ditunjukkan nilai $\mathrm{k}=0,0021 \mathrm{~L} \mathrm{mg}^{-1}$ menit ${ }^{1}$ dan $\mathrm{R}^{2}=0,9178$.

\section{DAFTAR PUSTAKA}

Awaluddin, A., Agustina, M., Aulia, R. R., Muhdarina. 2017. Precursor effects on the morphology and crystallinity of manganese oxides and their catalytic application for methylene blue degradation. AIP Conference Proceedings. 1823: 020108.

Cheng, G., Yu, L., Lin, T., Yang, R., Sun,
M., Lan, B., Deng, F. 2014. A facile one-pot hydrothermal synthesis of $\beta$ $\mathrm{MnO}_{2}$ nanopincers and their catalytic degradation of methylene blue. Journal of Solid State Chemistry, 217, 57-63.

Cui, H.J., Hai-Zhen, H., Fu, M.-L., Yuan, B.L., Pearl, W. 2011. Facile synthesis and catalytic properties of single crystalline $\quad \beta-\mathrm{MnO}_{2} \quad$ nanorods. Catalysis Communications, 12, 1339-1343.

Liu, Y., Chao Luo, C., Sun, J., Li, H., Sun, Z., and Shiqiang Yan, S., 2015. Enhanced adsorption removal of methyl orange from aqueous solution by nanostructured proton-containing $\delta$-MnO2. Journal of Environmental Science, 10.

Park, H., Choi, W. 2003. Visible Light and $\mathrm{Fe}$ (III)-Mediated Degradation of Acid Orange 7 in the Absence of $\mathrm{H}_{2} \mathrm{O}_{2}$. J. Photochem. Photobiol., A. 159: 241. 
Siregar, S. dan Awaluddin, A. 2018. Synthesis and catalytic activity of Birnessite-Type Manganese Oxide synthesized by solvent-free method. IOP Conference Series: Materials Science and Engineering. 345:

012005 